\title{
PENGOPTIMALISASIAN KETERAMPILAN \\ LITERASI INFORMASI ILMIAH GURU PENDIDIKAN AGAMA ISLAM
}

\author{
Dian Hasfera*, Lailatur Rahmi*, Fadhila Nurul Husna Zalmi*, \& \\ Resty Jayanti Fakhlina*
}

*Jurusan Ilmu Perpustakaan, Universitas Islam Negeri Imam Bonjol

Email korespondensi: lailaturrahmi@uinib.ac.id

(Submitted: 29-11-2019, Revised: 26-03-2020, Accepted: 01-06-2020)

DOI: $10.24252 /$ kah.v8i1a8

\begin{abstract}
ABSTRAK: Literasi informasi dalam setiap aspek pengetahuan dan pembelajaran sangat penting untuk terus dikembangkan, khususnya untuk pembelajaran agama Islam. Gerakan literasi informasi perlu ditanamkan dalam setiap jenjang pendidikan sejak dini di bangku sekolah, tujuannya untuk mendidik siswa agar 'melek' terhadap perkembangan ilmu pengetahuan khususnya pengetahuan agama Islam. Penelitian kualitatif deskriptif ini menggambarkan bagaimana model keterampilan literasi guru Pendidikan Agama Islam di Kota Padang. Data penelitian diperoleh melalui kuesioner dan wawancara langsung dengan komunitas Majlis Guru Mata Pelajaran Pendidikan Agama Islam (MGMP-PAI) tingkat SMA se kota padang yang beranggotakan 50 orang dan 3 pengawas. Hasil penelitian ini menunjukkan bahwa Guru PAI tingkat SMA perlu mengoptimalkan keterampilan literasi informasi agar dapat menyebarkan pengetahuan agama dari berbagai sumber informasi yang akurat dan terbebas dari "hoax information". Selain itu, terdapat empat model keterampilan literasi informasi guru dalam penelusuran informasi ilmiah yaitu skill mengidentifikasi fakta atau hoax, skill literasi informasi dalam pembelajaran, skill teknik penulisan ilmiah, dan skil temu balik informasi.
\end{abstract}

Kata kunci: Literasi informasi; model penelusuran informasi; kualitas guru

\section{ENHANCING INFORMATION LITERACY SKILLS FOR ISLAMIC HIGH SCHOOLS TEACHERS}

ABSTRACT: Information literacy in every aspect of knowledge and learning is very important to continue to be developed, particularly for Islamic religious learning. Information literacy needs to be instilled in every level of education in school, the aim is to educate students to be 'literate' towards the development of science, especially Islamic religious knowledge. This descriptive qualitative research illustrates how the model of information literacy skills of Islamic religious education teachers in Padang City. The research data were obtained through questionnaires and direct interviews with the Majlis Community Teachers of Islamic Religious Education Subjects (MGMP-PAI) at the high school level in Padang city with total of 50 members and 3 supervisors. The study indicated that Islamic religious education teachers in high school level need to optimize their information literacy skills so that they can spread religious knowledge from various sources of information that are accurate and free from "hoax". In addition, there are four models of information literacy skills in searching for scientific information, namely the skill of identifying facts or hoaxes, information literacy skills in learning, scientific writing technical skills, and information retrieval skills.

Keywords: Information literacy; information literacy models; teacher quality 


\section{PENDAHULUAN}

Menurut Bruce bahwa "Information literacy is a set of abilities requiring individuals to recognize when information is needed and have the ability to locate, evaluate, and use effectively the needed information", (American Library Association, 1989). "Information literacy is: 1) The use of information technology, 2) The use of information sources, 3) Executing a process, 4) Controlling information for retrieval, 5) Gaining knowledge, 6) Extending knowledge, and 7) Gaining wisdom (Bruce, 2003). Maksudnya ialah literasi informasi merupakan kemampuan untuk mengakses, mengevaluasi, mengorganisasi dan menggunakan informasi secara efektif untuk pembelajaran secara formal dan informal, memecahkan masalah, membuat keputusan dalam pekerjaan maupun pendidikan.

Pada dasarnya literasi informasi diartikan sebagai kemelekan huruf atau kemampuan membaca dan keaksaraan informasi manusia dalam kehidupan, terutama dalam pendidikan dan keagamaan. Di dalam ajaran Islam dipahami bahwa setiap Muslim harus, bahkan wajib mampu membaca dan menulis. Hal ini ditandai dengan wahyu yang pertama sekali diturunkan oleh Allah Subhanahu wa ta'ala kepada rasul-Nya Nabi Muhammad SAW, dalam surah al-'Alaq:1-5,

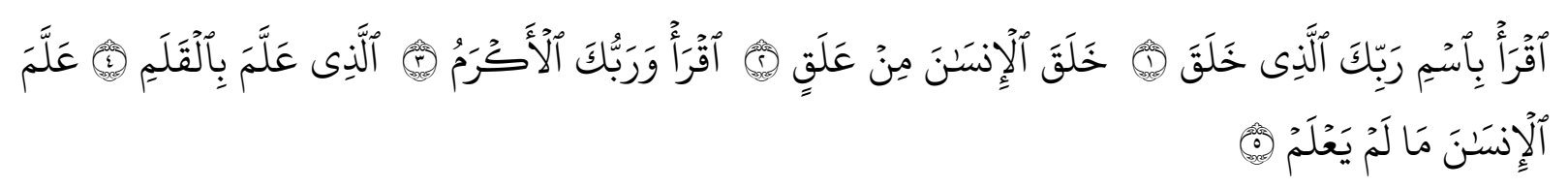

"Bacalah dengan nama Tuhanmu yang telah menciptakan, yang telah menciptakan manusia dari segumpal darah. Bacalah, dan Tuhanmulah yang Maha Mulia. Yang mengajar manusia dengan perantaraan penadan. Dia yang mengajar manusia tentang apa apa yang tidak diketahuinya".

Dalam ayat di atas sudah jelas sekali jika budaya baca tulis sangat berpengaruh terhadap peradaban dan juga berpengaruh terhadap kesadaran serta tingkah laku umat Islam untuk berbudaya baca dan tulis. Motivasi yang dimunculkan dari ayat-ayat Alqur'an tidak lain sebagai embrio lahirnya intelektualitas dalam Islam.

Tenaga pendidik dan perpustakaan sekolah memiliki peran penting dalam mendidik siswa agar melek informasi termasuk untuk mata pelajaran Pengetahuan Agama Islam (PAI). Peran itu justru merupakan tanggung jawab bagi guru Pendidikan Agama Islam di sekolah, terutama di Sekolah Menengah Atas sebagai jenjang pendidikan untuk mendidik "remaja kekinian" yang sangat mudah dipengaruhi oleh berbagai macam informasi. Peran Guru PAI dalam memperhatikan arus deras informasi adalah dengan menanamkan kepada siswa agar melek informasi terutama untuk perkembangan sumber ilmu pengetahuan agama islam. Mendidik siswa agar mampu berpikir kritis dalam menganalisis kebutuhan informasi siswa, membiasakan siswa untuk dapat mengevaluasi informasi yang didapatkan dengan mudah melalui jejaring internet dan media sosial.

Pendidikan yang profesional akan mempengaruhi kualitas lulusan ke depan, maka guru memiliki tanggung jawab besar dalam mendidik siswa yang salah satunya dapat dilakukan melalui gerakan literasi informasi. Amerta Social Consulting and Resourcing (2015) menyatakan bahwa jika kualitas sumber daya manusia makin rendah, maka akan menimbulkan bencana besar untuk keberlanjutan bangsa. Melalui pencanangan program Masyarakat Ekonomi ASEAN (MEA), tenaga pendidik agar terus peduli dalam memperhatikan kompetensi siswa sesuai dengan bidang studi masing-masing. Tujuannya nanti agar siswa dapat melek terhadap informasi dan terciptanya lulusan yang berkompetensi di bidangnya (AMERTA, 2015).

Hal tersebut sesuai dengan tujuan pendidikan Nasional yang tertera dalam Undang-Undang Sistem Pendidikan Nasional Nomor 20 tahun 2003 pada Pasal 1 yaitu "Pendidikan adalah usaha sadar dan terencana untuk mewujudkan suasana belajar dan proses pembelajaran agar peserta didik secara aktif mengembangkan potensi dirinya untuk memiliki kekuatan spiritual keagamaan, pengendalian diri, kepribadian, kecerdasan, akhlak mulia, serta keterampilan yang diperlukan 
dirinya, masyarakat, bangsa dan negara", (UUD RI No. 20 Tahun 2003 Tentang Sistem Pendidikan Nasional).

Dari hasil observasi dan wawancara dengan beberapa informan yang merupakan guru PAI tingkat SMA Kota Padang, umumnya masih belum optimalnya kemampuan literasi informasi para guru PAI dalam membantu proses pembelajaran. Pelaksanaan pembelajaran di kelas yang menggunakan kurikulum Nasional menuntut mahasiswa aktif belajar, mencari dan mendapatkan dan menganalisa bahasan studi agama dari berbagai sumber informasi. Namun perhatian khusus belum ditekankan pada pilihan sumber informasi yang benar bagi siswa, termasuk untuk mengevaluasi informasi akhir yang didapat oleh siswa. Hal ini bisa dipengaruhi oleh beberapa faktor bagi Guru PAI di SMA Kota Padang, baik itu dari tingkat usia, gagap teknologi dan kurang optimal dalam literasi informasi. Maka untuk itu perlu dilakukan pengoptimalisasian kemampuan literasi informasi di Majlis Guru Mata Pelarajan (MGMP) PAI SMA Kota Padang.

Guru PAI di sekolah pada akhirnya memilki tantangan yang sangat besar dalam mengoptimalisasikan gerakan literasi informasi. Melihat kebutuhan siswa yang sangat luas dalam akses informasi dalam proses pembelajaran. Apalagi melihat keberadaan teknologi informasi yang terus membuat siapa saja 'haus' akan informasi. Akan tetapi, mendapatkan informasi tanpa batas akan menjadi 'boomerang' tersendiri bagi guru di sekolah jika dirinya sendiri tidak terarah dengan baik dalam mengevaluasi informasi ilmiah yang ditemukan pada dunia maya. Dampak buruk yang perlu ditekankan oleh para guru PAI saat ini adalah hoax dan plagiarisme yang sangat diharamkan dalam proses pembelajaran di sekolah apalagi untuk pelajaran agama. Melihat kondisi ini, maka jalan keluar yang perlu dilakukan untuk mencegah fenomena di atas adalah guru PAI perlu membudayakan gerakan literasi informasi untuk mengoptimalisasikan keterampilan tenaga pengajar dalam mencari, mengorganisir serta mengevaluasi informasi agar dapat dimanfaatkan secara efektif dan efisien.

\section{METODOLOGI PENELITIAN}

Metode penelitian yang digunakan dalam penelitian ini adalah kualitatif deskriptif. Penelitian ini menggambarkan fenomena yang diungkapkan terkait topik yang dibahas. Populasi dari penelitian ini adalah seluruh anggota Majlis Guru Mata Pelajaran Pendidikan Agama Islam (MGMP-PAI) Kota Padang. Pengumpulan data kualitatif bersifat interaktif yang memiliki langkahlangkah yang saling berkaitan. Menurut Syaodih (2011) terdapat 5 tahapan dalam pengumpulan dan analisis data yaitu perencanaan, memulai pengumpulan data, pengumpulan data dasar, pengumpulan data penutup, dan melengkapi data-data yang sudah didapatkan. Peneliti menggunakan tahapan-tahapan tersebut.

\section{HASIL DAN PEMBAHASAN}

Majlis Guru Mata Pelajaran (MGMP) adalah suatu wadah tempat berkumpulnya guru mata pelajaran PAI untuk saling berkomunikasi dan saling bertukar informasi yang bertujuan untuk meningkatkan kualitas guru dan mutu pembelajaran PAI. MGMP merupakan wadah professional bagi para guru agama untuk meningkatkan pengetahuan dan kemampuan serta keterampilan fungsional antara sesama guru agama dengan memanfaatkan kemampuan masing-masing guru dalam menyatukan visi untuk melakukan sistem pengajaran yang lebih baik, lebih efektif, dan berhasil guna serta memperoleh informasi terkini.

Dari kegiatan yang dilakukan, maka dihasilkan sebuah model keterampilan literasi informasi guru dalam penelusuran informasi ilmiah sebagai berikut: 


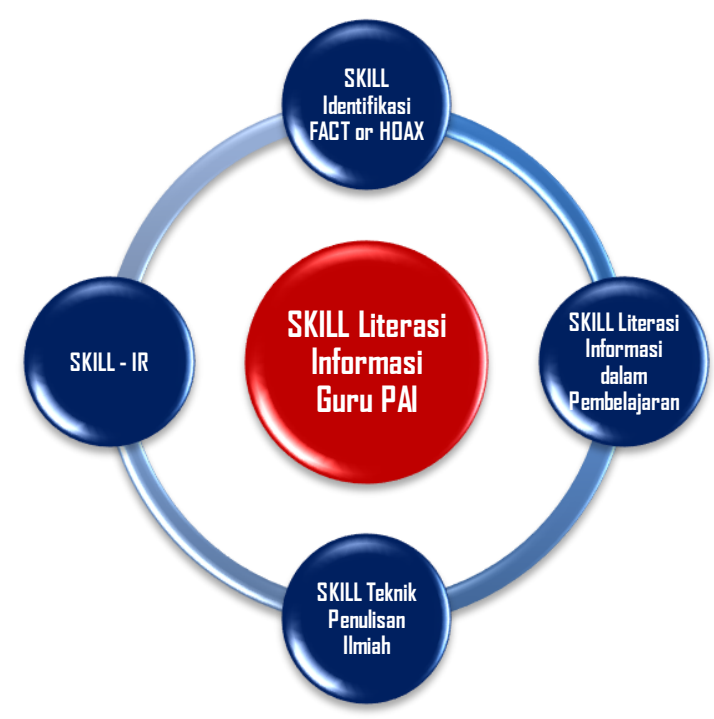

Gambar 1. Model keterampilan literasi informasi guru dalam penulusuran informasi ilmiah

Berikut penjelasan gambar di atas.

\section{Skill Identifikasi Fact or Hoax}

Hoax adalah suatu kata yang digunakan untuk menunjukan pemberitaan palsu atau usaha untuk menipu atau mengakali pembaca untuk mempercayai sesuatu. Pemberitaan yang tidak berdasarkan kenyataan atau kebenaran (non factual) untuk maksud tertentu. State University of New York, "literasi informasi sebagai kemampuan untuk mengenali saat informasi dibutuhkan, ditempatkan, dievaluasi untuk kemudian digunakan secara efektif dan sekaligus mengkomunikasikannya ke dalam berbagai bentuk dan jenis". Untuk mencegah penyebaran dan penggunaan berita hoax maka: dilakukan kegiatan literasi informasi untuk mendidik pemustaka di dalam menyaring, memahami dan mengevaluasi informasi yang baru didapatkan sebelum dilanjutkan untuk digunakan dan disebarluaskan.

Pengenalan literasi informasi ini penting untuk menyamakan pandangan pihak-pihak terkait tentang pentingnya pemahaman guru tentang literasi informasi saat ini dan menanamkan budaya literasi di sekolah melalui berbagai kegiatan. Materi yang diberikan meliputi pengenalan dasar literasi informasi, literasi informasi vs hoax, menanamkan budaya literasi dan penanaman literasi informasi dalam setiap kegiatan di sekolah.

\section{Skill Literasi Informasi dalam Pembelajaran}

Materi yang diberikan adalah Literasi Indonesia di Rangking Dunia, Penanaman Budaya Literasi pada Guru dan Siswa, Literasi Informasi di Era Revolusi Industri 4.0. Sharing kegiatan literasi informasi dengan guru-guru peserta mengenai pentingnya literasi informasi dalam pembelajaran di sekolah. Meliputi Perkembangan Literasi Informasi di sekolah dan pentingnya ditanamkan untuk para siswa oleh guru melalui budaya literasi.

\section{Skill Teknik Penulisan Ilmiah}

Hal yang perlu diperhatikan yaitu penempatan level untuk pembuatan daftar isi dan hal-hal terkait mengenai bibliografi atau daftar pustaka. Penggunaan software pendukung sitasi akan mempermudah kita, karena sitasi akan tersusun secara otomatis dari entry yang dimasukkan. Halhal yang dapat dilakukan untuk mempertimbangkan keakuratan suatu informasi:

a. Berfikir kritis terhadap informasi

b. Budaya literasi yaitu kemampuan melek informasi dan evaluasi 
Untuk dapat mencegah hoax tersebut, maka dilakukan kegiatan literasi informasi untuk mendidik pemustaka di dalam menyaring, memahami dan mengevaluasi informasi yang baru di dapatkan sebelum dilanjutkan untuk digunakan dan disebarluaskan. Materi yang dapat diberikan berupa;

a. Pengenalan model-model penulisan daftar pustaka dari berbagai sumber

b. Penomoran otomatis dan daftar isi, pengutipan bodynote dan footnote

Meningkatnya semangat praktek guru terutama dalam pembuatan daftar isi, penomoran dan sitasi bibliografi/praktek menggunakan Ms. Word.

\section{Skill Information Retrieval}

Kegiatan yang disosialisasikan dimulai dari menentukan kebutuhan informasi, strategi pencarian, menentukan sumber informasi yang akan ditelusur, penelusuran menggunakan teknik, menemukan informasi dan memilih informasi yang sesuai dengankebutuhan. Menanamkan kepada guru PAI untuk mempraktekkan konsep blended learning dalam mendukung proses pembelajaran. Penanaman diberikan melalui pengenalan guru PAI terhadap konsep penelusuran informasi.

Penelusuran online merupakan proses Sistem Temu Balik Informasi (STBI) yang berperan dalam pemanggilan dokumen elektronik. Penelusuran online memanfaatkan bantuan mesin pencarian (search engine) sebagai penghubung antara pengguna dengan informasi yang terdapat di internet. Penelusuran online merupakan sarana dalam akses temu kembali informasi yang berfungsi sebagai penghubung antarmuka (interface) pengguna dengan sumber daya informasi yang terdapat di dalam database. Dalam penelusuran online dibutuhkan strategi maupun kebijakan dalam penelusuran informasi untuk mendapatkan informasi yang relevan dengan kebutuhan. Materi yang diberikan adalah.

a. Pengenalan dan praktek strategi penelusuran informasi ilmiah, meliputi; bolean loogic dan advanced search google.

b. Database populer, meliputi; google cendikia, garuda Dikti dan e-resources Perpustakaan Nasional (Perpusnas) RI.

Guru-guru mendapatkan pengalaman baru dalam menguasai strategi pencarian yang efektif. Meningkatnya partisipasi peserta dalam praktek. Guru berhasil membuat akun menjadi anggota Perpusnas dan menelusur berbagai macam sumber relevan. Kegiatan peningkatan literasi informasi untuk Guru PAI ini dapat dilakukan berdasarkan beberapa kegiatan yang tergambar pada tabel berikut:

Tabel 1. Hasil Kegiatan Pengabdian

\begin{tabular}{|c|c|c|}
\hline No & Tema Kegiatan & Materi Kegiatan dan Capaian \\
\hline \multirow[t]{2}{*}{1} & $\begin{array}{lll}\text { Knowledge } & \text { Sharing } & 1\end{array}$ & Pengenelan dasar literasi informasi, literasi informasi \\
\hline & $\begin{array}{l}\text { "Pengenalan Literasi Informasi } \\
\text { pada Guru" }\end{array}$ & $\begin{array}{l}\text { vs informasi hoax, net generation } \\
\text { - } \quad \text { Antusias para guru dalam memperhatikan materi dan } \\
\text { berdiskusi dengan narasumber terkait materi. }\end{array}$ \\
\hline \multirow[t]{2}{*}{2} & $\begin{array}{lrr}\text { Knowledge } & \text { Sharing } 2 & \text { "Urgensi } \\
\text { Literasi } & \text { Informasi } & \text { pada } \\
\text { Pembelajaran Sekolah" } & \end{array}$ & $\begin{array}{l}\text { - Perkembangan Literasi Informasi di sekolah dan } \\
\text { pentingnya ditanamkan untuk para siswa oleh guru } \\
\text { melalui budaya literasi di sekolah. }\end{array}$ \\
\hline & & $\begin{array}{l}\text { - Meningkatkannya antusias para guru dalam } \\
\text { menanggapi ulasan narasumber dan mengaitkannya } \\
\text { dengan praktek di lapangan oleh beberapa guru. }\end{array}$ \\
\hline
\end{tabular}


3 Knowledge Sharing 3 "Strategi - Pengenalan Model-model Penulisan Daftar Pustaka dan Teknik Penulisan Ilmiah" dari berbagai sumber

- Penomoran automatis dan daftar isi Pengutipan bodynote dan footnote

- Meningkatnya semangat praktek guru terutama dalam pembuatan daftar isi, penomoran dan sitasi bibliografi/ praktek menggunakan Ms. Word.

$4 \quad$ Knowledge Sharing 4 "Strategi Penelusuran Informasi Ilmiah dan Pengenalan Database Populer"
- Pengenalan dan praktek Strategi Penelusuran Informasi Ilmiah, meliputi; bolean loogic dan advanced search google

- Database Populer, meliputi; google cendikia, garuda dikti dan e-resourch perpusnas.

- guru-guru mendapatkan pengalaman baru dalam menguasai strategi pencarian yang efektif.

- Meningkatnya partisipasi peserta dalam praktek

- Guru berhasil membuat akun menjadi anggota perpusnas dan menelusur berbagai macam sumber relevan

\section{DISKUSI}

Dari apa yang diperoleh, para guru sudah dapat memulai merumuskan informasi terkait materi yang akan diberikan kepada siswa, kemudian membuat pertanyaan-pertanyaan untuk mendefenisikan informasi tersebut. Mereka mengidentifikasi referensi yang dibutuhkan terkait dengan masalah yang akan dibahas. Selanjutnya menentukan tema atau topik informasi terlebih dahulu sebelum mencari informasi untuk siswa.

Para guru PAI sudah dapat menentukan sumber informasi yang akan dicari terkait dengan topik bahasan dengan menggunakan media cetak dan digital dari berbagai sumber informasi yang ada. Selain itu, mereka juga menggunakan sumber informasi yang dilihat dari segi otoritif, kebaharuan dan akurasi sumber informasi. Mereka sudah mulai aktif menggunakan search engine (mesin pencari) dalam pencarian informasi, serta dapat menemukan sumber informasi berdasarkan fokus mata pelajaran. Informasi yang diperoleh pun dapat dipilah dan diringkas, yang kemudian dapat menggunakan ide, pendapat pernyataan dari orang lain baik tertulis/lisan yang relevan sesuai dengan kebutuhan siswa dari berbagai sumber informasi. Para guru juga sudah mulai melakukan analisis terhadap berbagai informasi dari sumber yang ada dengan mencocokan informasi tersebut dengan mind mapping yang telah dibuat sebelumnya. Ini terlihat dari bagaimana mereka menulis informasi yang didapat dengan urutan ide, merumuskan masalah, identifikasi sumber, menggunakan mengakses informasi, membuat outline dan mengedit hasil akhir. Dengan menggunakan alat bantu lain dalam mengerjakan produk informasi, yaitu Microsoft Excel, Power Point, dan Microsoft Word. Dari sana, mereka kemudian menyatukan mencetak informasi yang diperoleh dalam bentuk kliping/bundle.

\section{KESIMPULAN}

Literasi informasi dalam setiap aspek pengetahuan dan pembelajaran sangat penting sekali untuk terus dikembangkan, khususnya untuk pembelajaran Pendidikan Agama Islam. Jika tingkat literasi informasi mengenai pembelajaran agama mulai merosot, lambat laun akan mempengaruhi akhlak generasi muda dan memberikan dampak negatif dalam kehidupan sosial masyarakat. Pentingnya gerakan literasi perlu ditanamkan dalam setiap jenjang pendidikan sejak dini di bangku sekolah, tujuannya untuk mendidik siswa yang 'literat' (keberinformasian) terhadap perkembangan ilmu pengetahuan khususnya pengetahuan agama Islam. Seyogyanya sekolah formal memiliki tanggung jawab besar untuk mendidik akhlak siswa agar memiliki bekal agama dan memiliki pemikiran yang kritis yang ditunjang dengan berbagai unsur termasuk perpustakaan. 


\section{DAFTAR PUSTAKA}

AMERTA Social Consulting \& Resourcing. "Survey Bisnis Indonesia: SDM Indonesia Tidak Kompetitif." Blog, 2015. http://www.amerta.id/2015/02/17/1068/survey-bisnisindonesia-sdmindonesia-tidak-kompetitif.php.

Arifin Z. Evaluasi Pembelajaran: Prinsip, Teknik, Prosedur. Bandung: Remaja Rosdakarya, 2013.

Arifianto. (2013). Balitbang Kominfo. Retrieved from https://balitbangsdm.kominfo.go.id/publikasi-indikator-tik-9.html

Arifin, Z. (2013). Evaluasi Pembelajaran: Prinsip, Teknik, Prosedur. Bandung: Remaja Rosdakarya.

Boyer, E. L. (1997). New Technologies and the Public Interest. Princeton, N.J: Carnegie Foundation for the.

Bruce, C. Seven Faces of Information Literacy Today's themes, 2003.

Catts, R. \&. (2008). Toward Information Literacy Indicator. Paris.

G. Sax. Principles of Educational and Psychological Measurement and Evaluation. Belmont California: Wads Worth Pub. Co., 1980.

Hancock, V. (2004). Information Literacy for Lifelong Learning. Retrieved from http://www.ericdigests.org/lifelong.html

Kulthau, C. C. (2004). Seeking Meaning : A Process Approach to Library and Information Services. Westport: Libraries Unlimited.

Lau, J. (2006). Guidelines on Information Literacy for Lifelong Learning. Mexico: IFLA. Retrieved from http://www.ifla.org/files/assets/information-literacy/publications /iflaguidelinesen.pdf

Muhaimin. (2009). Pengembangan Kurikulum Pendidikan Agama Islam di Sekolah, Madrasah, dan Perguruan Tinggi. Jakarta: RajaGrafindo.

Mukhsin. (2012). Model Pembelajaran Untuk Meningkatkan Kemampuan Berpikir Kritis Siswa. Bandung: Universitas Pendidikan Indonesia.

Musfah, J. (2015). Peningkatan Kompetensi Guru Melalui Pelatihan dan Sumber Belajar. Jakarta: Prenadamedia Group.

Rindyasari. (2008). Literasi Informasi Guru: Studi Kasus SMA Perguruan Islam Al Izhar Pondok Labu. Depok: Universitas Indonesia Fakultas Ilmu Pengetahuan Budaya Salmubi.

Romdhoni, A. (2013). Al-Qur'an dan Literasi (Sejarah Membangun Ilmu-ilmu Keislaman). Depok: Literatur Nusantara.

Sax, G. (1980). Principles of Educational and Psychological Measurement and Evaluation. Belmont California: Wads Worth Pub.Co.

Subali, B. (2014). Evaluasi Pembelajaran (Proses Dan Produk). Purwokerto: Universitas Muhammadiyah Purwokerto.

Sulistyo-Basuki. (2013). Literasi Informasi Dan Literasi Digital. Retrieved from https://sulistyobasuki.wordpress.com/2013/03/25/literasi-informasi-dan-literasidigital

Sya'rawi. (2006). Tafsir Sya'rawi Jilid 3 Juz V dan Juz VI An-Nisa 24 s/d Al Maidah 81. Medan: Duta Azhar.

Undang-Undang Republik Indonesia Nomor 20 Tahun 2003 Tentang Sistem Pendidikan Nasional 